\title{
Testing and Development of a 30-kVA Hybrid Inverter: Lessons Learned and Reliability Implications
}

\author{
Jerry W. Ginn ${ }^{*}$ \\ Photovoltaic System Components Department, Sandia National Laboratories, Albuquerque, New MAPCE
}

\section{SUMMARY}

A 30-kVA Trace Technologies hybrid power processor was specified and extensively tested at the Sandia inverter test facility. Trace Technologies made modifications, primarily involving the control system, in response to suggestions by Sandia and Arizona Public Service (APS) personnel. The modifications should make the inverter more universally applicable and less site-specific so that it can be applied in various sites with minimal field interaction required from the design engineer. The project emphasized the importance of battery management, generator selection, and site load management to the performance and reliability of hybrid power systems.

\section{INTRODUCTION}

Arizona Public Service (APS) had need of a 30-kVA inverter for use in their STAR facility test bed to investigate the operation of photovoltaic (PV)-hybrid systems that are presently being deployed in their service area. Objectives of the project were (1) to provide APS with a

${ }^{*}$ Correspondence to: Jerry Ginn, Sandia National Laboratories, P. O. Box 5800, Albuquerque, NM 87185-0753. E-mail: jwginn@sandia.gov, www.sandia.gov/pv

Sandia is a multi-program laboratory operated by Sandia Corporation, a Lockheed Martin Company, for the U.S. Department of Energy under contract DE-AC04-94AL8500. 


\section{DISCLAIMER}

This report was prepared as an account of work sponsored by an agency of the United States Government. Neither the United States Government nor any agency thereof, nor any of their employees, make any warranty, express or implied, or assumes any legal liability or responsibility for the accuracy, completeness, or usefulness of any information, apparatus, product, or process disclosed, or represents that its use would not infringe privately owned rights. Reference herein to any specific commercial product, process, or service by trade name, trademark, manufacturer, or otherwise does not necessarily constitute or imply its endorsement, recommendation, or favoring by the United States Government or any agency thereof. The views and opinions of authors expressed herein do not necessarily state or reflect those of the United States Government or any agency thereof. 


\section{DISCLAIMER}

Portions of this document may be illegible in electronic image products. Images are produced from the best available original document. 
useful tool for their research, (2) to assist in the development of PV-hybrid power-processing products, and (3) to enhance understanding of hybrid power-processing issues.

\section{HYBRID POWER SYSTEM DEFINITION}

A hybrid power system is defined as one having more than one source of electrical power. One of the sources is usually an engine-generator, and the other(s) some combination of renewable sources such as PV.

\section{WHY HYBRIDS?}

The interest within the PV community in hybrids arose from analysis of remote power systems consisting only of engine generators. Although engine-generators are a mature technology, some issues existed with these systems. These issues included reliability, fuel cost (which can be driven by the cost of delivery to remote locations), maintenance, and environmental concerns. In sites having varying loads, problems were exacerbated by the fact that generators had to be sized to meet peak load requirements. In many cases, this resulted in the generator running at very low loading for most of the time, thus lowering engine efficiency. As a first step to improving engine performance, batteries and a power conditioner (inverter) were added to a generator-only system with the goals of (1) fully loading the engine, (2) reducing engine run time, and (3) adding a period of redundancy (that is, since there are now two ac sources, if one fails, the other can carry the load while troubleshooting and repair are carried out). Analyses of such systems showed them to be technically and economically promising ${ }^{1}$, so with the batteries and inverter in place, some type of renewable 
could be added as a secondary charging source with the goal of further reducing the engine run time. The economics of adding a renewable source are site-specific. Analyses have been performed for several cases. ${ }^{2}$

\section{BACKGROUND OF PROJECT}

Arizona Public Service required a 30-kVA hybrid inverter for their STAR test facility. APS had identified a number of potential hybrid sites in their service area and planned to develop a test bed for evaluating hybrid operation and performing preliminary testing before deploying new equipment. The inverter was to be integrated with a bank of tubular gel batteries of a new type that was developed jointly by Yuasa and by Sandia's Energy Storage Systems Department specifically for hybrid applications. This was viewed as an opportunity by Sandia's PV System Applications Department. Some large hybrid systems have experienced reliability problems that may be attributed to their unique, site-specific designs. With that in

mind, a specification was developed jointly between Sandia and Trace Technologies for a replicable design of a $30-\mathrm{kW}$ hybrid power processor as a first step toward standardization. The unit was specified to have identical power electronics to those of another $30-\mathrm{kW}$ inverter that was being built by trace Technologies for the U. S. Navy at Santa Cruz Island. The inverter was to be tested at Sandia and provided to APS for use in their STAR facility.

\section{DESCRIPTION}

Figure 1 shows a single-line diagram of the power processor. Although the entire unit is generically referred to as an "inverter," it actually consists of three power electronics 
converters. The first--the PV peak power tracker--converts the maximum available power from a PV array to an intermediate dc link in a dc-to-dc conversion. The second--the battery charge controller--is another dc-to-dc converter that passes energy between the battery and the dc link either to provide power to the loads or, in the other direction, to charge the battery. The third--the inverter/rectifier--is a dc-to-ac converter that either inverts the dc link energy to ac for the loads or, when charging from an external ac generator, rectifies the ac to dc for charging the battery. An external transformer provides the required voltage and isolation. The power-processor's integral ac switchgear enclosure includes a bypass switch so that loads can continue to be fed by the generator if maintenance is required for either the inverter or the transformer. In normal operation, when the battery reaches a low state of charge, the inverter's controls start the engine-generator and bring it online by closing the contacts shown. At that point, loads are fed directly by the generator and any excess power is used to recharge the battery.

\section{ENHANCEMENTS RESULTING FROM SNL TESTING}

During the course of testing at Sandia, a number of issues were identified. All were addressed by Trace Technologies in a cooperative, cost-sharing effort. Table 1 lists the major developmental changes. These primarily involved the control system and were made in response to suggestions by Sandia and Arizona Public Service personnel. The primary concern expressed by APS was reliability. Conditions that could result in a loss of load should be minimized. The following is a brief discussion of three of the items. 
As noted in item 7, difficulty was experienced resulting from the use of a generator with an inadequate governor. Because this $30 \mathrm{~kW}$ generator could not power more than $24 \mathrm{~kW}$ of load, its frequency sagged unacceptably, resulting in inverter trips. To minimize this problem and to make the inverter more flexible, capability was added to input the generator capacity from the inverter control panel, as opposed to the fixed generator size that was previously programmed into the inverter. This permits use of a smaller generator.

The inverter was developed with the capability to operate in parallel with the generator to feed larger loads than either could power individually. This capability was only available when the generator was charging batteries. As item 4 shows, the unit was modified so that an overload that occurs during inverter operation causes the generator to start and operate in parallel with the inverter.

Figure 2 demonstrates the manner in which the inverter supports the generator as well as its full loading of the generator while charging batteries. With no load applied, all the generator power is used to charge batteries. As the system load is increased, battery-charging power is proportionately reduced to maintain constant loading of the generator. When the load is increased beyond the generator rating, the inverter draws power from the batteries to support the load. The change from charge to discharge mode occurs seamlessly. The limit of parallel support is determined by the bulk charging current limit set in the inverter control panel.

Temperature compensation had been based on a temperature derived from an external data-acquisition system via a serial port to the inverter controls. As noted in item 15, a direct battery temperature input was added. At the same time, a battery-temperature fault condition 
was added. This is potentially a very important feature as batteries have been shown to overheat while charging them when they are near their end of life.

\section{LESSONS LEARNED}

The project provided insight into hybrid system design and operation in three areas; namely, battery management, generator selection, and site load management.

\section{Battery Management}

The primary lesson learned regarding proper battery charging is: Any PV hybrid battery management strategy should limit the number of days the battery spends in a deficit charge condition and provide a means for full recovery ("equalization") of that battery on a regular basis $^{3}$

\section{Charge Algorithm}

Figure 3 shows the charge cycle used by the Trace Technologies hybrid inverter. The values shown were chosen for illustration purposes only and are not intended as recommended values. At the beginning of Figure 3, the system is operating in inverter mode. When the battery voltage drops below the generator-start-voltage setting, the inverter controls detect that fact, start the generator and begin charging the battery.

\section{Bulk Charge}


The initial bulk charge would normally occur at a fixed current setting; however, in Figure 3 the bulk charge current is increased as the sun comes up and the PV array contributes more energy to battery-charging.

\section{Finish Charge (current taper)}

When the battery voltage reaches its regulation charge voltage setting, the charge current is gradually reduced to maintain this voltage value. This process continues until the current has tapered to its end-of-charge setting. At this time, a "normal" charge cycle is completed and the system controls would turn off the generator and return to inverter operation. The Trace inverter allows programming of time intervals between equalization charges. In the example illustrated by Figure 3, a time interval between equalizations has been chosen such that the controls proceed to perform an equalization charge.

\section{Bulk Equalization}

As in the normal bulk charge, the current is maintained at a bulk setting as the battery voltage increases to its equalization setting.

\section{Current Taper}

As in normal finish charge, the current is tapered to maintain a constant equalization voltage. This process continues until the required current has tapered to its end-of-charge setting.

\section{Timed Equalization}

When the current has tapered to its end-of-charge setting, an equalization timer is started. The battery voltage is maintained at its equalize setting for a period of time. The intent of the selected time is to allow equalization to continue until equalizing current stabilizes. Note that in Figure 3 this period was set to 30 minutes, whereas in practice it would be on the order of 3 
to 12 hours; therefore, the equalizing current is still tapering and has not stabilized. At the end of this time interval, the controls turn off the generator and return to inverter operation.

\section{Discussion}

System life-cycle cost depends heavily on battery lifetime. On a life-cycle-cost basis, the battery can be the most expensive system component. Maximizing the life of the battery is therefore an important consideration. The following discussion is based on lead-acid batteries.

Most batteries are used in float applications, wherein they are maintained at a $100 \%$ state-of-charge for the vast majority of their lives and are rarely discharged. Since float applications account for the majority of battery sales, information from battery manufacturers is primarily oriented toward float service. However, all PV applications continuously cycle the battery state-of-charge. Requirements for charging in cycling applications are different from those in float. Specifically, a higher charge voltage is required both for flooded and valve-regulated batteries. In addition, a longer duration finish charge is required for valveregulated batteries than for flooded.

In hybrid systems, the battery state-of-charge is only estimated, either by counting ampere-hours or, more crudely, by measuring battery voltage. With either method, a charge deficit can build, resulting in battery damage or degradation. To minimize this capacity loss, batteries require a complete finish charge. During a complete finish charge, the battery is maintained at an elevated regulation voltage for an extended period of time. The term "finish charge" and "equalization" are used interchangeably, but a true equalization period begins 
when finish charging ends, that is, after the current required to maintain the elevated voltage has tapered to an extremely low value. In either case, the economic penalty consists of extended engine-generator run time at low loading.

Table 2 shows suggested settings for charging flooded (vented) lead-acid batteries. These values are not intended to replace manufacturer's recommendation, but to give general guidelines. They are based on data from a variety of laboratory and fielded battery systems. ${ }^{3}$ Table 3 gives suggested settings for valve-regulated lead-acid batteries. In all cases, the battery manufacturer should be considered the ultimate authority.

\section{Generator Selection}

An inadequate generator places unrealistic demands on the control system. The problem encountered in the present project was a lack of adequate frequency regulation on the part of the generator.

\section{Gradual Application of Load To Generator}

To avoid unnecessarily block loading the generator, the power-processor should transfer loads to the generator gradually. For example, Figure 4 shows the gradual increase of generator current by the Trace Technologies hybrid as battery charging begins.

\section{Steady-State}

The change in steady-state generator frequency from no load to full load is defined as droop. There are two choices to minimize droop. First, a larger generator can be used. This is 
commonly done, but results in operating at lower loading and therefore lower efficiency. Thus this is not the preferred option. A better choice is the use of an isochronous governor, which by definition has zero droop. Such governors are available even on relatively small generators.

\section{Transient}

Application of a sudden large load (block load) can cause a generator to stop or dramatically change frequency. Transient response to a block load is affected by many factors, among which are generator size, engine size, fuel type, and governor type. The potential hybrid site should be evaluated to determine if a step load would be applied that is a significant fraction of the generator rating. If so, then that fact should be specified to the generator provider, who can take it into consideration in providing the right generator system for the site.

\section{Site Load Management}

Site load management has for years been a crucial part of stand-alone PV system design. It is just as crucial with large hybrid systems.

The ability to handle short-term overloads such as motor starts is important. Figure 5 shows the start of a 10-hp motor while a $6.4-\mathrm{kW}$ resistive load was in place. The motor was fully loaded mechanically by a dynamometer brake. During the period of startup, the motor attempts to draw on the order of 6.5 times its rated current. However, in order to protect the power electronics, the inverter controls limit the ac current. When this current limit is reached, application of any further load forces the voltage to sag. 
Addition of the overload generator-start capability (item 4 in Table 1) insured that if such an overload persisted for more than 2 seconds, the generator would be started and the load would be powered by the parallel combination of generator and inverter. Therefore, load power would not be lost. Even though there would be no blackout, there would still be a large voltage sag for many seconds.

The lesson learned from this exercise is that some type of reduced-voltage starter or soft starter should be considered for motors that are significant fractions of the inverter rating. Installation of such relatively inexpensive equipment can enhance performance significantly and should be considered a routine part of site load management when installing a PV-hybrid system.

Where the possibility exists, simultaneous starting of multiple motors can and should be prevented by the use of timing relays.

In addition to motor loads, a computer or other sensitive electronic load should be protected by an uninterruptible power supply (UPS). These are inexpensive and readily available.

\section{CONCLUSIONS}

An extended development test time led to a number of improvements to the $30-\mathrm{kVA}$ Trace Technologies hybrid inverter. The control changes identified by Sandia and by APS were implemented by Trace Technologies. They should make the inverter more universally applicable and less site-specific so that it can be applied in various sites with minimal field 
interaction required from the design engineer. The project emphasized the fact that key issues affecting the performance and reliability of hybrid systems are battery management, generator selection, and site load management. The inverter is presently being operated at the APS STAR hybrid test facility.

\section{REFERENCES}

1. G. Jones and R. Chapman, "Photovoltaic/Diesel Hybrid Systems: The Design Process," Proceedings of the Nineteenth IEEE Photovoltaic Specialists Conference, New Orleans, Louisiana, 1024-1030, May 1987.

2. R. N. Chapman, "Hybrid Power Technology for Remote Military Facilities," Proceedings of the Ninth International Power Systems World '96 Conference, Las Vegas Nevada, 415-427, September 7-13, 1996.

3. T. D. Hund, "PV Battery Storage: A Status Report," 1998 Photovoltaic Performance and Reliability Workshop, Cocoa Beach, Florida, November 3-5, 1998. 


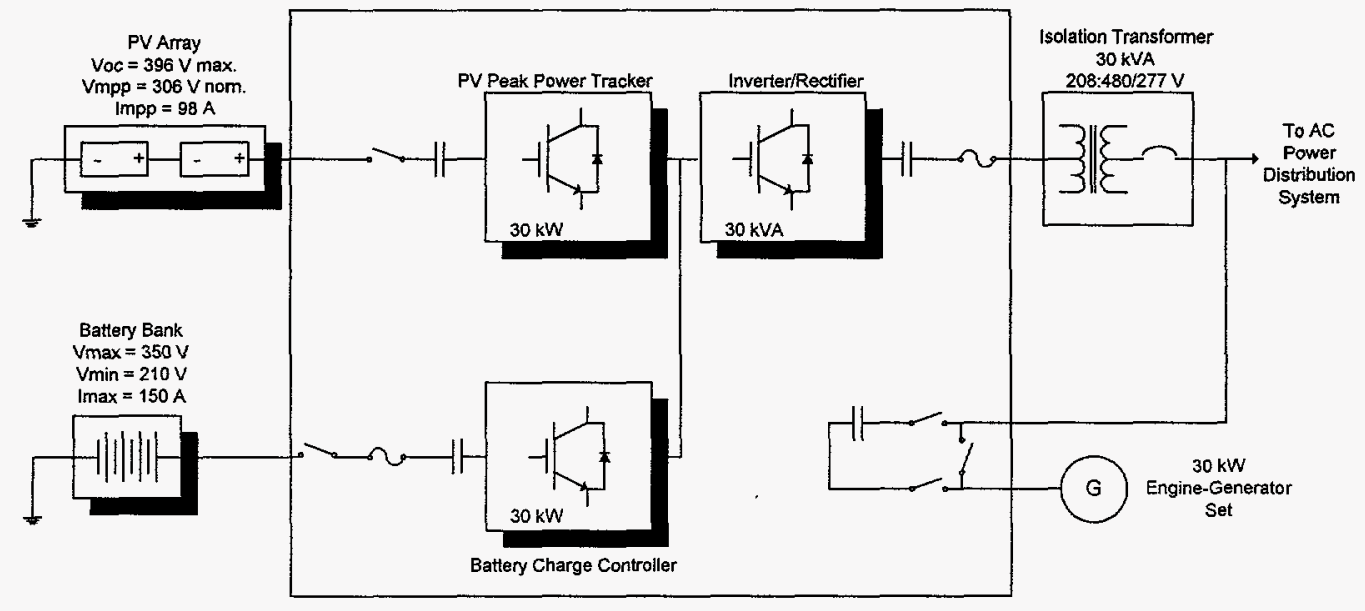

Figure 1. Single-line diagram 


\begin{tabular}{|c|c|c|}
\hline & Problem & Modification \\
\hline 1 & Terminology confusing & "Generator Only" replaces "Shutdown" \\
\hline 2 & Blackout if generator fails to start & $\begin{array}{l}\text { Inverter supports load to battery low-voltage disconnect } \\
\text { "Generator Fault" contacts added }\end{array}$ \\
\hline 3 & 10-hp motor start causes overload trip & Overload capability increased in controls \\
\hline 4 & No parallel capability during overloads in INV mode & Capability added \\
\hline 5 & Automatic restart of inverter following generator fault & Capability added \\
\hline 6 & Charge loads generator too rapidly & Slowed to 8-sec ramp \\
\hline 7 & $\begin{array}{l}\text { Small or poorly-regulated generator makes system } \\
\text { unstable }\end{array}$ & Front-panel selection of generator size added \\
\hline 8 & $\begin{array}{l}\text { Inverter output capacitors reduce useful charging capacity } \\
\text { from generator }\end{array}$ & $\begin{array}{l}\text { Reactive power now provided from inverter } \\
\text { More generator power available for charging }\end{array}$ \\
\hline 9 & PV not operating at max power point & $\begin{array}{l}\text { Current and time step controls added } \\
\text { Max power point agrees with } \mathrm{I}-\mathrm{V} \text { curve measurements }\end{array}$ \\
\hline 10 & $\begin{array}{l}\text { PV power motoring generator with light loads and charged } \\
\text { battery }\end{array}$ & Reverse-power protection added \\
\hline 11 & Charge may terminate prematurely due to large loads & Additional test forces complete charge \\
\hline 12 & Equalization may be inadequate due to large loads & Additional test forces complete equalization time \\
\hline 13 & No provision for generator "quiet time" & Quiet time added \\
\hline 14 & No direct battery temperature input & $\begin{array}{l}\text { Temperature input added to controls } \\
\text { Transducer and power supply provided } \\
\text { "Battery temperature out of range" fault condition added }\end{array}$ \\
\hline 15 & Documentation of user settings and factory de & Improved manual provided \\
\hline
\end{tabular}

Table 1. Developmental changes resulting from SNL/APS evaluation 


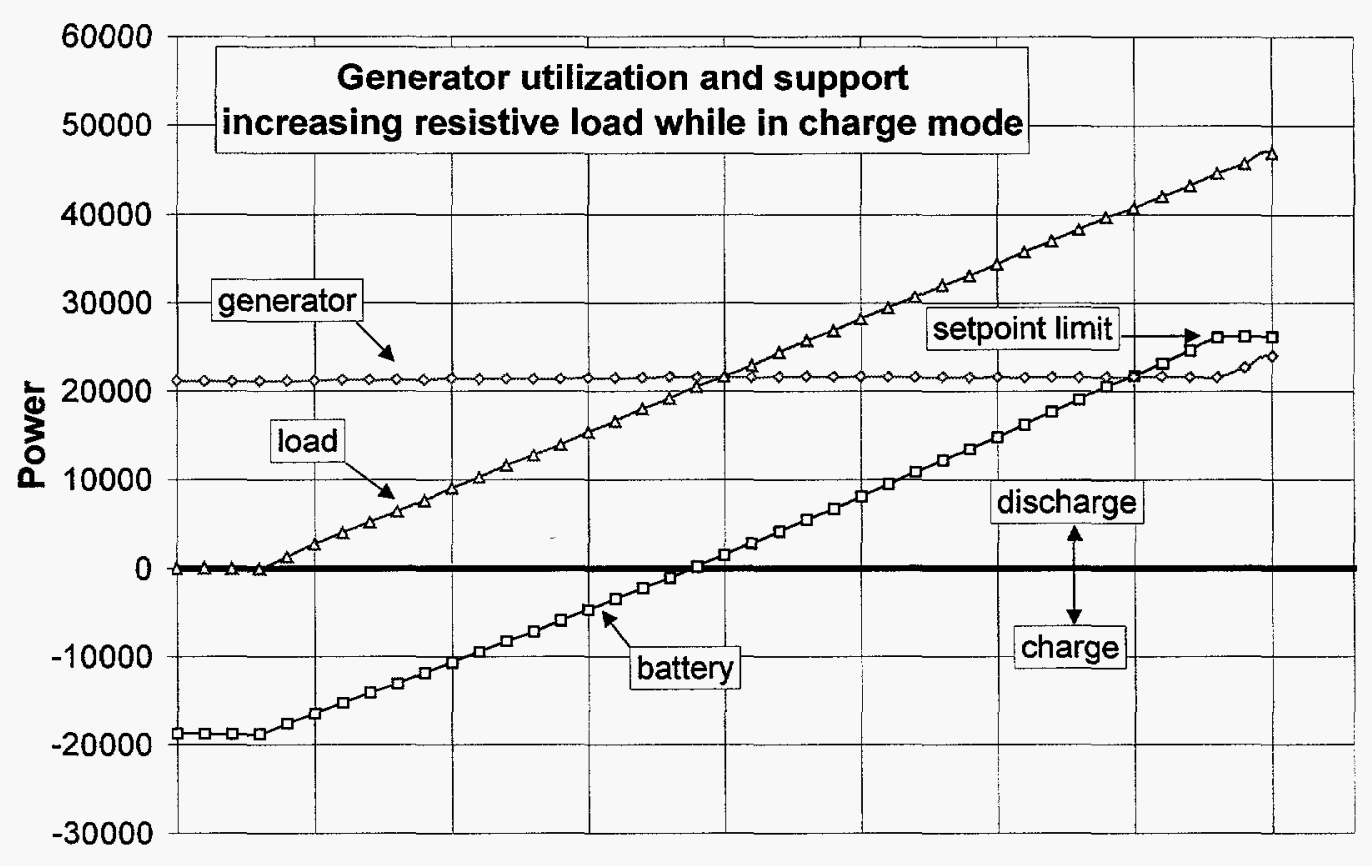

Figure 2. Increasing resistive load while charging batteries 


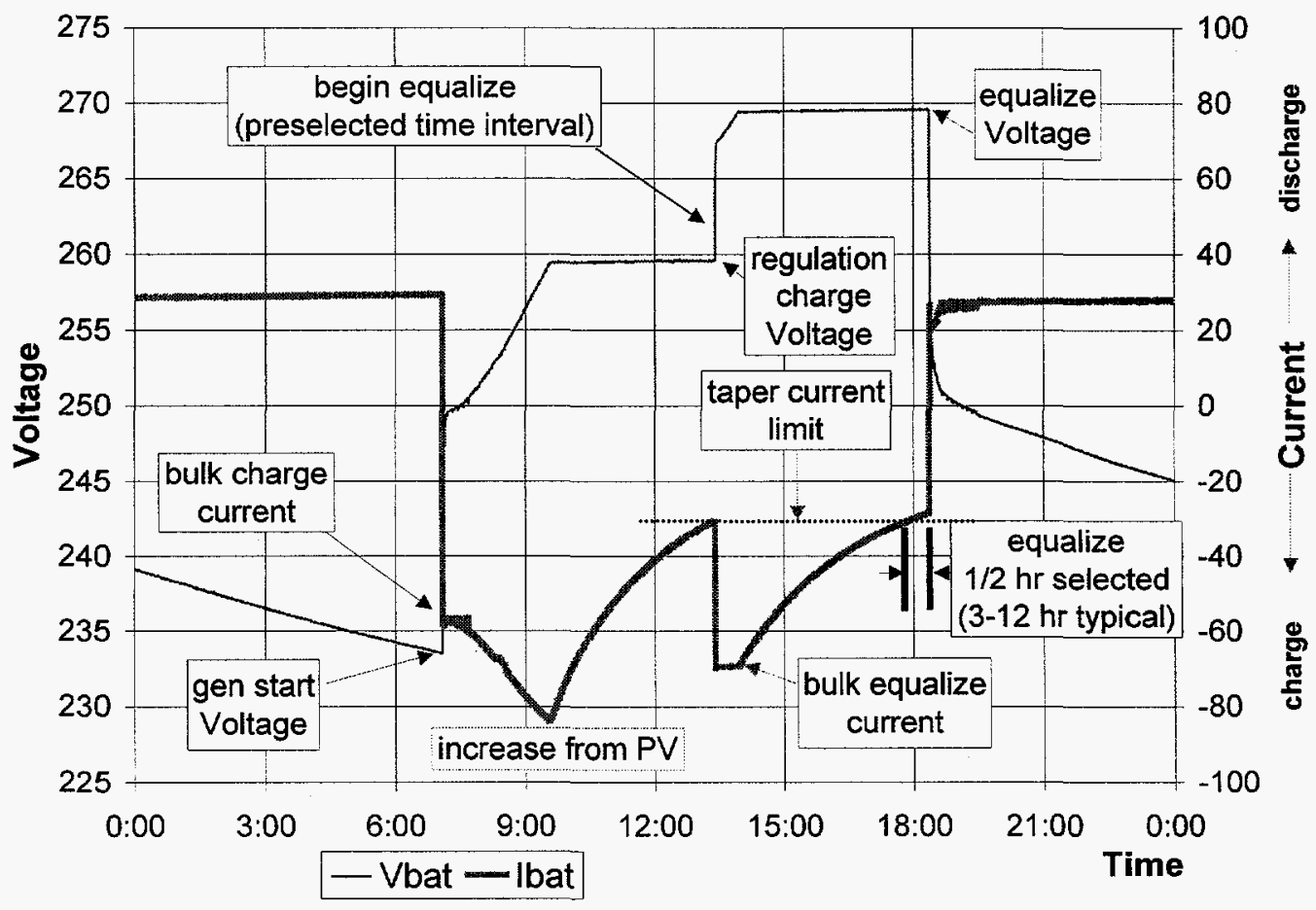

Figure 3. Battery charge algorithm. [Note: values $(v, i, t)$ for illustration only] 


\begin{tabular}{|c|c|c|}
\hline Variable & $\begin{array}{c}\text { Minimum } \\
\text { Lead-Antimony }\end{array}$ & $\begin{array}{l}\text { Maximum/Equalize } \\
\text { Lead-Antimony }\end{array}$ \\
\hline $\begin{array}{l}\text { PV Regulation Voltage } \\
\text { (Vr)@ } 25^{\circ} \mathrm{C}\end{array}$ & $\begin{array}{l}14.4 / 2.40 \mathrm{vpc} \text { Constant Voltage } \\
14.7-13.5 / 2.45-2.28 \mathrm{vpc} \text { On-Off }\end{array}$ & $\begin{array}{l}15.3 / 2.55 \text { vpc Constant Voltage } \\
15.3-13.7 / 2.55-2.28 \mathrm{vpc} \text { On-Off }\end{array}$ \\
\hline $\begin{array}{l}\text { Engine Generator } \\
\operatorname{Vr} @ 25^{\circ} \mathrm{C}\end{array}$ & $\begin{array}{c}14.4 / 2.40 \mathrm{vpc} \\
\text { to } \\
15.3 / 2.55 \mathrm{vpc}\end{array}$ & $15.3 / 2.55 \mathrm{vpc}$ \\
\hline Engine Generator Time@ Vr & $\begin{array}{l}0 \text { to } 3 \mathrm{hr} \text {. } \\
\text { (Bulk Charge, } 3 \text {-day max interval) }\end{array}$ & $\begin{array}{c}5 \text { to } 12 \mathrm{hr} . \\
\text { (15-day max interval) }\end{array}$ \\
\hline Engine Start Voltage & $\begin{array}{c}11.7 / 1.95 \mathrm{vpc} \\
(12.0 / 2.0 \text { typical })\end{array}$ & \\
\hline Low Voltage Disconnect (LVD) & $11.4 / 1.9 \mathrm{vpc}$ & \\
\hline Temperature Coefficient & $-0.005 \mathrm{~V} /{ }^{\circ} \mathrm{C} /$ cell & \\
\hline
\end{tabular}

Table 2. Flooded (vented) lead-acid battery suggested setpoints to obtain rated battery cycle life 


\begin{tabular}{|c|c|c|}
\hline Variable & $\begin{array}{l}\text { Minimum } \\
\text { VRLA }\end{array}$ & $\begin{array}{c}\text { Maximum/Equalize } \\
\text { VRLA }\end{array}$ \\
\hline $\begin{array}{l}\text { PV Regulation Voltage } \\
\text { (Vr) @ } 25^{\circ} \mathrm{C} \\
\text { (Constant Voltage Charging) }\end{array}$ & $\begin{array}{c}14.1 / 2.35 \mathrm{vpc} \\
\text { or } \\
14.4 / 2.40 \mathrm{vpc}\end{array}$ & $\begin{array}{l}14.1 / 2.35 \mathrm{vpc} \\
\text { or } \\
14.4 / 2.40 \mathrm{vpc}\end{array}$ \\
\hline $\begin{array}{l}\text { Engine Generator } \\
\mathrm{Vr} @ 25^{\circ} \mathrm{C} \\
\text { (Constant Voltage Charging) }\end{array}$ & $\begin{array}{l}14.1 / 2.35 \mathrm{vpc} \\
\text { or } \\
14.4 / 2.40 \mathrm{vpc}\end{array}$ & $\begin{array}{c}14.1 / 2.35 \mathrm{vpc} \\
\text { or } \\
14.4 / 2.40 \mathrm{vpc}\end{array}$ \\
\hline Engine Generator Time@Vr & $\begin{array}{l}0 \text { to } 6 \mathrm{hr} \text {. } \\
\text { (Assumes engine-gen finish chg) }\end{array}$ & $\begin{array}{c}12 \mathrm{hr} . \\
\text { (7-15-day max interval } \\
\text { dep on system design) }\end{array}$ \\
\hline Engine Start Voltage & $\begin{array}{c}11.7 / 1.95 \mathrm{vpc} \\
(12.0 / 2.0 \mathrm{vpc} \text { typical })\end{array}$ & \\
\hline Low Voltage Disconnect (LVD) & $11.5 / 1.92 \mathrm{vpc}$ & \\
\hline Temperature Coefficient & $-0.005 \mathrm{~V} /{ }^{\circ} \mathrm{C} /$ cell & \\
\hline
\end{tabular}

Table 3. VRLA (sealed) lead-acid battery suggested setpoints to obtain rated battery cycle life 


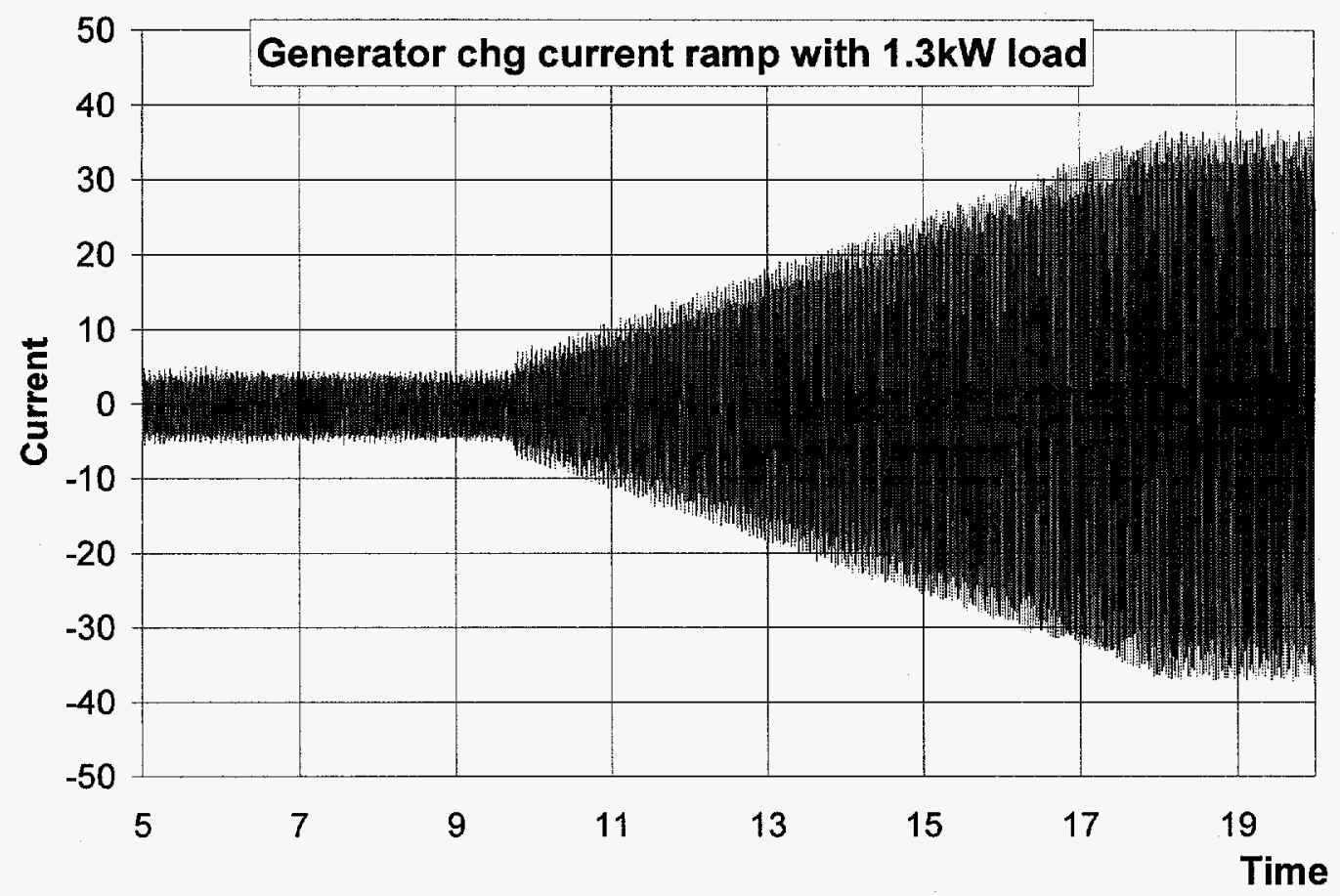

Figure 4. Gradual application of charging load to generator 


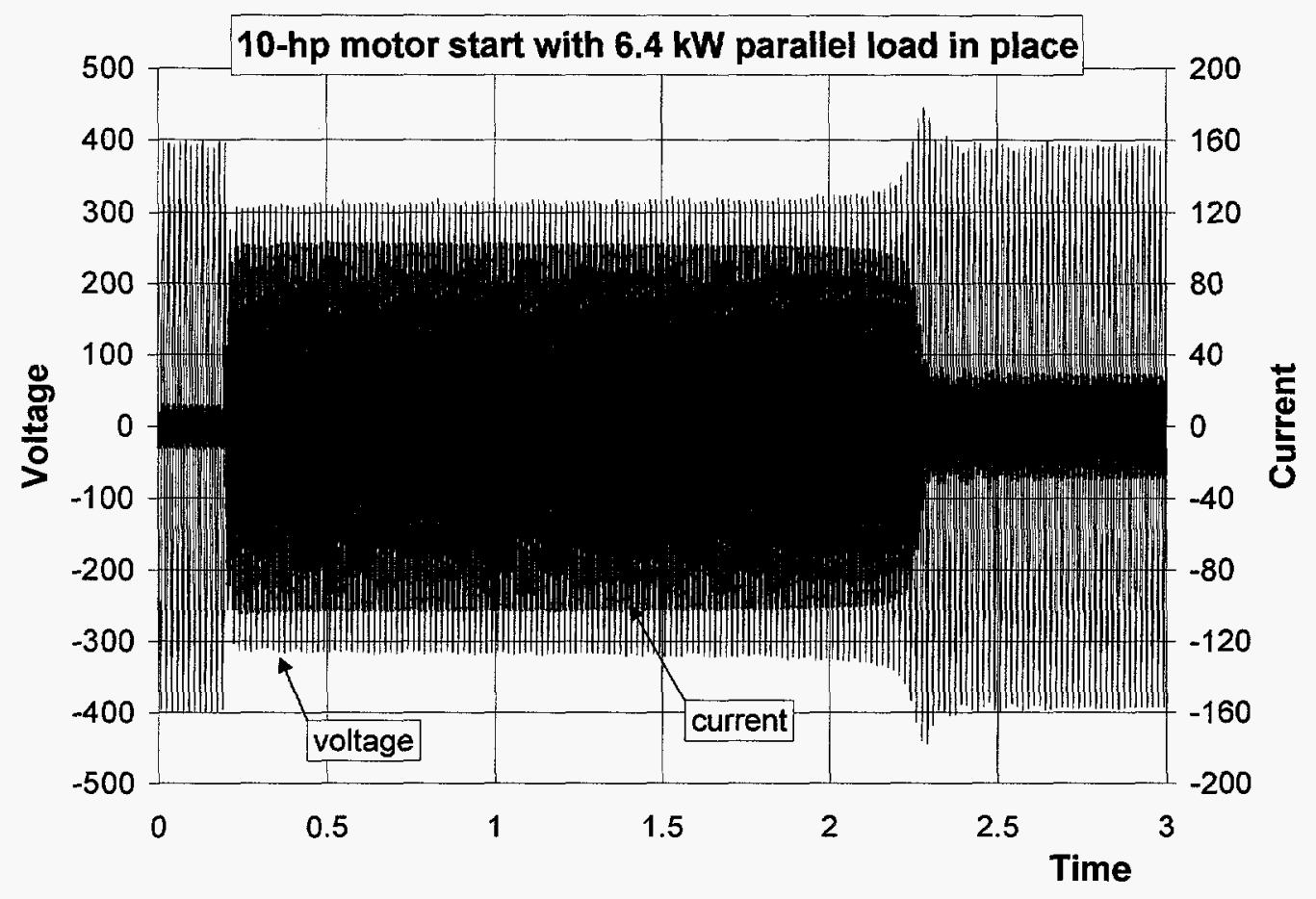

Figure 5. Voltage sag resulting from motor start 